Volume 16

October 2015

\title{
Self-Governance by Humanitarian Non-State Actors in Health and Nutrition Relief
}

Shahla Ali

Tom Kabau

Follow this and additional works at: https://via.library.depaul.edu/jhcl

\section{Recommended Citation}

Shahla Ali \& Tom Kabau, Self-Governance by Humanitarian Non-State Actors in Health and Nutrition Relief, 16 DePaul J. Health Care L. 141 (2014)

Available at: https://via.library.depaul.edu/jhcl/vol16/iss2/3

This Article is brought to you for free and open access by the College of Law at Digital Commons@DePaul. It has been accepted for inclusion in DePaul Journal of Health Care Law by an authorized editor of Digital Commons@DePaul. For more information, please contact digitalservices@depaul.edu. 


\title{
SELF-GOVERNANCE BY HUMANITARIAN NON-STATE ACTORS IN HEALTH AND NUTRITION RELIEF
}

\author{
Shahla $\mathrm{Ali}^{\ddagger}$, Tom Kabau*
}

The provision of food and nutrition relief has generally comprised the largest share of international humanitarian resources in cases of complex humanitarian disasters. ' Given that poor quality or unsuitable health assistance can have grossly negative consequences such as 'increased morbidity, mortality, and disability,' increasingly, humanitarian agencies are recognizing the need for a common set of standards and guiding principles for humanitarian health assistance. ${ }^{2}$ The central argument postulated in this paper is that despite the absence of a proper global legal enforcement mechanism of the obligation to provide quality humanitarian assistance in health and nutrition, emerging self-governing mechanisms, such as the Sphere Humanitarian Charter, provides a useful mechanism for self-regulation and action by civil society organizations. Such selfregulatory mechanisms contribute to the development of international customary law with regard to an emerging responsibility to provide effective humanitarian assistance.

\section{INTRODUCTION: ACCOUNTABILITY AND EFFICIENCY IN GLOBAL CONTEXT}

While, states presently bear primary responsibility in the implementation of humanitarian relief in the health and nutrition sector, in recent years, members of the international community have recognized the need for greater accountability and standard setting in humanitarian health

\footnotetext{
$\ddagger$ Assistant Professor and Deputy Director, Program in Arbitration and Dispute Resolution, Faculty of Law, University of Hong Kong. B.A., Stanford University; J.D. and Ph.D, Boalt Hall School of Law, University of California at Berkeley. The author thanks the Government of Hong Kong's University Grants Committee for its kind support through its ECS Grant (HKU 757412H).

* Senior Lecturer, Africa Nazarene University Law School. Ph.D. in Public International Law, University of Hong Kong; LL.M. and LL.B., University of Nairobi. Previous Research Fellow, Utrecht University.

1 Helen Young, Public Nutrition in Emergencies: An Overview of Debates, Dilemmas and Decisionmaking, 23 DISASTERS 277, 277-78 (1990).

2 Nicholas Banatvala \& Anthony B Zwi, Public Health and Humanitarian Interventions: Developing the Evidence Base, 321 BRIT. MED. J. 101, 102 (2000).
} 
service delivery. This gap-filling mechanism of international selfregulatory entities reflects insights of new governance literature of the emerging role of the state as facilitator of humanitarian action.

The 1998 Guiding Principles on Internal Displacement by the General Assembly contain specific provisions on health humanitarian assistance. Principle 19(1) of the Guiding Principles provides that:

All wounded and sick internally displaced persons as well as those with disabilities shall receive to the fullest extent practicable and with the least possible delay, the medical care and attention they require, without distinction on any grounds other than medical ones. When necessary, internally displaced persons shall have access to psychological and social services. ${ }^{3}$

While such guiding principles clearly outline the responsibility to provide medical care and service to the wounded and sick, international actors have noted the critical need for "universal minimum standards, key criteria and benchmarks for the purpose of ensuring quality and accountability" in humanitarian assistance activities. ${ }^{4}$ As a result, the key challenge in the effective implementation of humanitarian obligations is the attempt to "apply a uniform set of standards," even in radically different situations and circumstances. ${ }^{5}$ In order to overcome this challenge, The Sphere Project was initiated in 1987 by non-governmental organizations as a way of establishing a universal self-regulatory mechanism that would contribute to accountability and efficiency in the delivery of humanitarian relief in critical areas such as health and nutrition. The Sphere Humanitarian Charter and Minimum Standards have been developed as a comprehensive guide for humanitarian agencies in the delivery of humanitarian relief.

The Sphere Project's Humanitarian Charter is premised on "the principle of humanity" and the existing legal framework of humanitarian assistance, such as "the rights to protection and assistance reflected in the provisions of international humanitarian law, human rights and refugee law." In some cases, some of the guidelines negotiated under the auspices

\footnotetext{
3 UnITEd Nations, Guiding Principles on Internal Displacement UN Doc E/CN.4/1998/53/Add.2 (1998), available at $\mathrm{http} / / \mathrm{www}$ l.umn.edu/humants/instree/GuidingPrinciplesonInternalDisplacement.htm.

4 Max R. O'Donnell, Dimitri Bacos \& Michael L. Bennish, Nutritional Response to the 1998 Bangladesh Flood Disaster: Sphere Minimum Standards in Disaster Response, 26 DISASTERS 229, 231-32 (2002).

5 Id. at 239.

6 Humanitarian Charter and Minimum Standards in Humanitarian Response, THE SPHERE PROJECT, 21 (2011), available at http://www.sphereproject.org/resources/download-publications/?search=1\&keywords= \&language $=$ English \&category $=22$.
} 
of international NGOs and civil societies may be adopted by the General Assembly, and therefore, acquire the beneficial authority of a "soft" law, and the capacity to be taken into account as part of state practice in the analysis of emerging international customary law. For instance, in Resolutions 63/139, 63/141 and 63/137 of 2008, the General Assembly adopted the Guidelines for the Domestic Facilitation and Regulation of International Disaster Relief and Initial Recovery Assistance ("IDRL Guidelines"), which were negotiated under the auspices of the International Federation of Red Cross and Red Crescent Societies ("IFRC"). ${ }^{7}$ The IDRL Guidelines are aimed at assisting governments to provide timely and quality humanitarian aid, in addition to addressing common legal challenges in international relief efforts. ${ }^{8}$

The Sphere Project is a significant mechanism for self-managed regulation, as it attempts to establish a link between obligations under international humanitarian and human rights law and the work of humanitarian organizations. ${ }^{9}$ It was an initiative of several NGOs and the International Red Cross and Red Crescent movement commencing in 1997. ${ }^{10}$ The objective of the founding NGOs was to ensure accountability in the provision of humanitarian assistance, in addition to improving the quality of aid. ${ }^{11}$ The Sphere Project is built on the philosophy that victims of humanitarian crisis "have a right to life with dignity and, therefore, a right to assistance; and second, that all possible steps should be taken to alleviate human suffering arising out of disaster or conflict."12 Based on that philosophy, the Sphere Humanitarian Charter establishes minimum standards on humanitarian assistance for food security, nutrition, and health, amongst other areas. ${ }^{13}$ The standards espoused under the Humanitarian Charter essentially set out the minimum conditions in humanitarian assistance programs for purposes of ensuring that the victims "survive and recover in stable conditions and with dignity." ${ }^{4}$ The general structure of the Humanitarian Charter is that minimum standards are prescribed in the delivery of critical forms of humanitarian assistance such as food and health aid, in addition to the inclusion of key indicators and

7 See IDRL Guidelines, INT'L FED. OF RED CROSS \& RED CRESCENT SOCIETIES (IFRC), http://www.ifrc.org/en/what-we-do/idrl/idrl-guidelines/ (last accessed May 10, 2013).

$8 \mathrm{Id}$.

9 Lola Gostelow, The Sphere Project: The Implications of Making Humanitarian Principles and Codes Work, 23 DISASTERS 316, 317-318 (1999).

10 THE SPHERE PROJECT, supra note 6.

$11 \mathrm{Id}$.

$12 \mathrm{Id}$.

$13 \mathrm{Id}$.

14 THE SPHERE PROJECT, supra note 6. 
guidance notes to enable humanitarian agencies monitor and evaluate their compliance with the standards. ${ }^{15}$

The development of the Sphere Project and the growing influence of its Humanitarian Charter within the humanitarian civil society organizations as a self-regulation mechanism is evidence of the emerging trend of global self-regulation. Heydebrand notes that:

Governance is defined as the existence of "regulatory mechanisms in a sphere of activity which function effectively even though they are not endowed with formal authority".... Common to most of these mechanisms is the possible transformation and replacement of law by non-legal and nongovernmental practices and procedures. A central challenge here is the need to rethink regulation and the emergence of quasilegal, regulatory mechanisms at the global level ....16

The Sphere Humanitarian Charter establishes a regulatory and accountability policy framework through input from a network of global NGOs. ${ }^{17}$ It demonstrates the role of such organizations in advancing accountability and quality in global humanitarian assistance activities. A significant contribution of the Sphere Humanitarian Charter, despite lack of binding legal authority, is that it constitutes a core policy document for self-regulation, accountability and minimum standards benchmarking by various civil society organizations and other humanitarian agencies. The standards enumerated in the Charter are critical technical guidelines that have been developed through the collective practical and on the ground experiences of the various humanitarian agencies that have participated in the Project. ${ }^{18}$ The standards are based on the need to enhance the accountability of humanitarian assistance agencies and generally improve the effectiveness of aid. ${ }^{19}$ The Sphere Humanitarian Charter has, in recent years, become one of the important regulators of humanitarian assistance in various disaster settings. ${ }^{20}$ It originated from discussions among NGOs with the objective that it would provide a practical set of standards and that

15 Charlotte Dufour, et al, Rights, Standards and Quality in a Complex Humanitarian Space: Is Sphere the Right Tool? 28 DISASTERS 124, 125.

16 Wolf Heydebrand, From Globalisation of Law to Law under Globalisation (found in ADAPTING LEGAL CULTURES 117, 120 (David Nelken and Johannes Feest eds.) (2001)..

17 Marci Van Dyke \& Ronald Waldman, The Sphere Project Evaluation Report, Mallman SCH. OF PUB. HEALTH COLUMBIA UNIV., 8 (Jan 2004), available at

http://www.unscn.org/layout/modules/resources/files/Evaluation_report.pdf.

18 O'Donnell, et al., supra note 4, at 232.

19 Dyke \& Waldman, supra at note 4.

20 ld. 
the success of the Project would not be disrupted by interagency rivalry. ${ }^{21}$ It arose out of a historical necessity for codes and standards for humanitarian assistance delivery. ${ }^{22}$

The suffering witnessed during the catastrophic 1994 Rwanda genocide influenced the desire to develop the Sphere standards, due to the widespread feeling across the humanitarian agencies that there was need for accountability and benchmarks. ${ }^{23}$ In the aftermath of the Rwanda genocide, there was a concerted effort to determine the factors that contributed to the failure of humanitarian aid, in addition to addressing issues of accountability. ${ }^{24}$ The outcome of such concerns within humanitarian agencies was the Humanitarian Charter and Minimum Standards Handbook under the Sphere Project. ${ }^{25}$

The Sphere Project Board is comprised of 18 organizations, which include International Medical Corps, International Federation of Red Cross and Red Crescent Societies, Aktion Deutschland Hilft, Office Africain pour le Développement et la Coopération, Sphere India, ACT Alliance/Norwegian Church Aid, CARE International, Caritas Internationalis, InterAction, International Council of Voluntary Agencies, World Vision International, Lutheran World Federation/DanChurchAid, Oxfam International, Plan International, Policy Action Group on Emergency Response, RedR International, Save the Children and the Salvation Army. ${ }^{26}$

There have been other efforts aimed at ensuring efficiency and accountability in the provision of humanitarian assistance. ${ }^{27}$ In addition to the Sphere Humanitarian Charter, there is the Humanitarian Accountability Project (HAP), which commenced as the Humanitarian Ombudsman Project. The Ombudsman project, conducted under the auspices of the British Red Cross, was initiated in the 1997 World Disasters Forum, with the objective of determining the viability of the establishment of an office that would be responsible for maintaining accountability in humanitarian

\footnotetext{
21 Peter Walker \& Susan Purdin, Birthing Sphere, 28 DiSASTERS 100, 102 (2004).

22 Id.

23 Lotus McDougal \& Jennifer Bear, Revisiting Sphere: New Standards of Service Delivery for New Trends in Protracted Displacement 35 DISASTERS 87, 90 (2011); see also, Jacqui Tong, Questionable Accountability: MSF and Sphere in 200328 DISASTERS 176, 176 (2004); Van Dyke \& Waldman, supra at 4. 24 Tong, supra at 176.

25 Id.

26 Board Organizations, THE SPHERE PROJECT,

http://www.sphereproject.org/sphere/en/about/governance/board-member-organizations/ (last accessed Oct. $22,2013)$.

27 Gostelow, supra note 9, at 316.
} 
assistance. ${ }^{28}$ The humanitarian catastrophe caused by the 1994 Rwanda genocide generated unprecedented concerns regarding the efficacy and accountability of relief agencies, and therefore, helped generate international consensus to address those issues. ${ }^{29}$ In particular, the failure of international actors to help prevent or effectively respond to the Rwanda genocide explicitly demonstrated that humanitarian agencies could also cause harm through omissions, by failing to act on their promises of protection and assistance. $^{30}$

In the aftermath of the genocide, the Joint Evaluation of the International Response to the Rwandan Genocide was established, and it recommended that organizations should improve their accountability by strengthening oversight mechanisms. ${ }^{31}$ The recommendations would lead to the launch of the Humanitarian Ombudsman Project in $1997 .{ }^{32}$ The Ombudsman Project promoted the push for the observance of key standards and codes of conduct in humanitarian assistance. ${ }^{33}$ The Ombudsman Project eventually evolved into the Humanitarian Accountability Project. ${ }^{34}$ The Humanitarian Accountability Partnership is a coalition of humanitarian agencies that have the objective of promoting accountability to the beneficiaries of relief through standards of accountability and quality implemented through mechanisms such as certification. $^{35}$ It is an institution through which beneficiaries and recipients of humanitarian aid can speak out regarding any grievances that they may have against relief agencies. ${ }^{36}$ The Ombudsman Project, currently the Humanitarian Accountability Partnership, has, however, been criticized for appearing to excuse "both the local authorities and the international community for deficiencies in providing for people's welfare by shifting the focus and responsibility for a population's welfare on to NGOs." 37

The objective of the Sphere Project is to promote accountability and effectiveness in the provision of humanitarian assistance by civil society

28 Id.

29 The History of HAP HUMANITARIAN ACCOUNTABILITY P'SHIP, http://www.hapinternational.org/whowe-are/about-us/the-history-of-hap.aspx (last accessed Oct. 30, 2013).

$30 \mathrm{Id}$.

31 HUMANITARIAN ACCOUNTABILITY P'SHIP, supra note 30.

32 Id.

33 Gostelow, supra note 9, at 316.

34 HUMANITARIAN ACCOUNTABILITY P'SHIP, supra note 30.

35 Id.

36 Tong, supra note 23, at 176.

37 Tong, supra note 23, at 186. 
organizations and donors. ${ }^{38}$ The Sphere Charter includes a common set of criteria for the evaluation of humanitarian programs. ${ }^{39}$ The Humanitarian Charter can be an important benchmark tool for use in advocacy aimed at civil society organizations, states, and other participants for the purposes of enhancing levels of service in humanitarian aid. ${ }^{40}$ It still reaffirms the role of the state, as the entity that bears the primary responsibility for the realization of the relevant humanitarian and human rights entitlements by its nationals. ${ }^{41}$ That way, the Charter reaffirms the view that a state should not obstruct the provision of humanitarian assistance by both local and international agencies where it is either unable or unwilling to provide the basic necessities to its citizens.

Following an introduction, this article will examine 1) the theoretical foundations of a human rights approach to humanitarian "legal" obligations; 2) the Sphere Humanitarian Charter applies this approach in its work in health and nutrition relief; and 3 ) the international and national legal frameworks of accountability in assessing health and nutrition relief work. Finally, it will conclude with policy recommendations on coordinating humanitarian assistance and institutional collaboration.

\section{PART I: A HUMAN RIGHTS APPROACH TO HUMANITARIAN 'LEGAL' OBLIGATIONS}

The Sphere Charter states that its standards and principles are premised on a rights-based approach to humanitarian assistance. ${ }^{42}$ It states that each of the minimum standards are premised on the "principle that disaster-affected populations have the right to life with dignity." Charter emphasizes the view that "people affected by disaster or conflict have a right to receive protection and assistance to ensure the basic conditions for life with dignity." 44 The Humanitarian Charter also states that its principles reflect obligations under international law, which have evolved from the elementary principle of a common humanity, and are universal in nature. ${ }^{45}$ Commentators have endorsed the view that the Sphere Humanitarian Charter is based on international human rights and

\footnotetext{
38 Gostelow, supra note 9, at 318.

$39 \mathrm{Id}$.

$40 \mathrm{Id}$.

41 Gostelow, supra note 9, at 318.

42 THE SPHERE PROJECT, supra note 6 , at 6

43 Id. at 7.

44 The SPHERE PROJECT, supra note 6, at 20. $45 \mathrm{Id}$.
} 
humanitarian law, including treaties and principles of the international legal system. For instance, it has been postulated that the Humanitarian Charter reflects an international human rights framework for issues relating to disaster management, public health and gender studies. ${ }^{46}$

In particular, the Charter affirms the view that its principles originate from "rights to protection and assistance reflected in the provisions of international humanitarian law, human rights and refugee law." Charter outlines the rights that victims affected by humanitarian catastrophes are entitled to, including the right to life with dignity, to receive humanitarian assistance, and to protection and security. ${ }^{48}$ According to the Humanitarian Charter, the right to good health and adequate food are protected by international law and form part of the right to life with dignity, which essentially translates to the right to receive humanitarian assistance. ${ }^{49}$

It has also been suggested that the Sphere Humanitarian Charter may contribute to the formation of international customary law with regard to "the rights of beneficiaries to a specific quality of response in humanitarian disaster while connecting these rights to universal principles of human dignity . . .." However, the development of the non-legal norms and standards stipulated under the Sphere Charter into rules of international customary law would require acceptability and endorsement by states, in the form of state practice and opinio juris. ${ }^{51}$ In addition, standards enshrined in the Charter can contribute to the conclusion of treaties or adoption of resolutions by states. Standards and norms by civil society organizations are important: besides being mechanisms for selfregulation, they can contribute to the making and implementation of international law when states are compelled to adopt them as treaties or "soft law" resolutions. For instance, in 1859, Henry Dunant's efforts to provide humanitarian assistance to the wounded soldiers in the battle of Solferino, by mobilizing local women, eventually led to the establishment

\footnotetext{
46 O'Donnell et. al., supra note 4, at 238.

47 THE SPHERE PROJECT, supra note 6, at 21. (The humanitarian Charter summarizes core legal principles that may be drawn from international instruments such as the Universal Declaration of Human Rights, the Geneva Conventions (on Intemational Humanitarian Law) and the 1951 Convention on the Status of Refugees); Dyke \& Waldman, supra at note 4, at 8.

48 THE SPHERE PROJECT, supra note 6, at 21.

$49 \mathrm{Id}$. at 22.

50 O'Donnell, supra note 4, at 238-39.

51 The International Court of Justice (ICJ) has reaffirmed that the formation of international customary law is dependent on both state practice and opinio juris. See Military and Paramilitary Activities in and Against Nicaragua (Nicar. v. U.S.), 1986 I.C.J. 14, I 107 (June 27) (merits); North Sea Continental Shelf Cases (Fed. Rep. of Ger./Den; Fed. Rep. of Ger./Neth.), 1969 I.C.J. 3, I 77 (Feb. 20) (Judgment).
} 
of the International Committee of the Red Cross (ICRC). ${ }^{52}$ The ICRC, despite not being an intergovernmental organization, has made significant contributions to the development of international humanitarian law, and vigorously encourages its implementation by governments and parties to armed conflicts. ${ }^{53}$ The ICRC was established in 1863, and in 1864, influenced states into adopting the first Geneva Convention, which "introduced a unified emblem for the medical services" and "obliged armies to care for wounded soldiers, whatever side they were on . . .."54

Some of the obligations endorsed in the Sphere Humanitarian Charter are certainly part of current treaty provisions and customary international law, but the issue of the existence of a right to humanitarian assistance, and the enforcement mechanisms of most obligations, are certainly not well-defined within the international legal system. The 1949 Geneva Conventions and the 1977 and 2005 Additional Protocols are important sources of international humanitarian law. ${ }^{55}$ With respect to food and nutrition aid, the 2012 Food Assistance Convention, which entered into force in 2013, has been ratified by Canada, Switzerland, United States, Austria, Denmark, European Union, Japan and Finland. ${ }^{56}$ Further, a 2005 study by the ICRC opined that failure to consent to the provision of humanitarian relief, which ends up threatening the survival of the civilian population, or contributes to severe starvation, may amount to a violation of customary international law. ${ }^{57}$ Further, while international humanitarian obligations are often primarily state duties, international agencies may

52 Peter Walker and Susan Purdin, 'Birthing Sphere' (2004) 28(2) Disasters 100-111, 101. 28 DiSASTERS 100,101 (2004).

53 History of the ICRC, INT'L COMM. OF THE RED Cross (ICRC) (Oct. 29, 2010), http://www.icrc.org/eng/who-we-are/histor y/overview-section-history-icrc.htm.

$54 \mathrm{Id}$.

55 Leonard Blazeby \& David Fisher, Promoting International Humanitarian Law and International Disaster Response Laws, Rules and Principles within the Commonwealth, 36 COMMONWEALTH LAW BULLETIN 709, 709 (2010); see Geneva Convention for the Amelioration of the Condition of the Wounded and Sick in Armed Forces in the Field (First Geneva Convention) (adopted 12 August 1949) 75 UNTS 31; Geneva Convention for the Amelioration of the Condition of Wounded, Sick and Shipwrecked Members of Armed Forces at Sea (Second Geneva Convention) (adopted 12 August 1949) 75 UNTS 85; Geneva Convention Relative to the Treatment of Prisoners of War (Third Geneva Convention) (adopted 12 August 1949) 75 UNTS 135; Geneva Convention Relative to the Protection of Civilian Persons in Time of War (Fourth Geneva Convention) (adopted 12 August 1949) 75 UNTS 287; Protocol Additional to the Geneva Conventions of 12 August 1949, and relating to the Protection of Victims of International Armed Conflicts (Protocol 1) (adopted 8 June 1977) 1125 UNTS 3; Protocol Additional to the Geneva Conventions of I2 August 1949, and relating to the Protection of Victims of Non-International Armed Conflicts (Protocol II) (adopted 8 June 1977) 1125 UNTS 609.

56 About FAC, FOOD ASSISTANCE CONVENTION,

http://www.foodassistanceconvention.org/en/about fac/about.aspx (last accessed May 10, 2013).

57 Rebecca Barber, Facilitating Humanitarian Assistance in International Humanitarian and Human Rights Law 91 INTERNATIONAL REVIEW OF THE RED CROSS 371, 372 (2009). 
have subsidiary responsibilities. For instance, while the primary responsibility to ensure the right to food lies with the state, it is also a shared obligation. ${ }^{58}$ Besides the state, individuals and non-state institutions also have a responsibility to protect and ensure realization of the right to food. ${ }^{59}$

However, the existence of various forms of obligations, and international legal instruments, aimed at ensuring the fulfillment of certain social, humanitarian and economic rights such as those relating to food and health, does not translate to a single, unified form of a legal right in the context of a "right to humanitarian assistance." As Kerchove and Ost opine, a legal system comprises of "properties that are not reducible to those characterizing its elements." right to assist which stipulates the duties of authorities and parties to a conflict in order to enable the delivery of relief services, and which lays out the responsibilities of humanitarian agencies" exists in international law, there is serious doubt that a right to assistance currently subsists in positive law. ${ }^{61}$

Despite the lack of a well-defined right to humanitarian assistance in international law, the Humanitarian Charter is based on a rights-based approach to humanitarian aid. ${ }^{62}$ The human rights approach under the Humanitarian Charter is, however, enhanced by the existence of the right to assist, which civil society organizations can base their actions when they intervene in disaster stricken states. The human rights approach is helpful in promoting humanitarian assistance as it revises the traditional foundations of relief in a fundamental way. ${ }^{63}$ Under the Humanitarian Charter, the provision of high quality humanitarian relief is reconceived from an act of kindness to that of a responsibility. ${ }^{64}$ The language of obligations, as opposed to kindness and concern, is likely to help muster the political and moral will to act by various agencies. As Evans points out, actions that involve "taking difficult political action" often require

58 Jean Drèze, Democracy and the Right to Food, ECON. \& POLITICAL WeEkLY 1723, 1726.

59 ld.

60 MiChel VAN DE KERCHOVE \& FRANÇOIS OST, LEGAL SYSTEM BETWEEN ORDER \& DisORdER 10 (Iain Stewart trans., 1994).

61 Charlotte Dufour, et al., Rights, Standards and Quality in a Complex Humanitarian Space: Is Sphere the Right Tool?, 28 DISASTERS 124, 130 (2004).

62 THE SPHERE PROJECT, supra note 6.

63 Dufour, supra at 126.

64 Dufour, supra at 126. 
robust and intelligent advancement of good arguments. ${ }^{65}$ Van Dyke and Waldman instructively observe that:

.... the adoption of a rights-based approach to humanitarian assistance represents a fundamental and drastic revision of the philosophy underlying emergency relief that prevailed prior to 1994 . . . . Instead, the Sphere Project sees international disaster response as an obligation, incurred by those who can help, to ensure that the rights of affected individuals and populations are respected and accorded. In other words, it is a bold and unequivocal assertion that providing relief to those made vulnerable by disaster is more than a good thing to do - it is an implementation of the law. ${ }^{66}$

Theoretically, the obligation to eliminate disparities in access to health may be justified on the basis of a social justice approach. ${ }^{67}$ Concerns about access to critical necessities such as food and health are issues related to the realization of social justice, which is an integral element of the human rights regime. ${ }^{68}$ That fact strengthens the place of humanitarian action under international law. The social justice approach is essentially a method of emphasizing "the moral imperative of eliminating glaring social inequality within societies and structurally-imbedded patterns of international support for those inequalities." 69

Despite the fact that the various rights that the Sphere Charter draws from in developing its principles and minimum standards are found in international legal instruments, most of those rights have serious justiciability and enforcement challenges. In particular, rights associated with access to good health and food are part of the social and economic rights which have serious enforcement problems even with regard to the state, the entity that is often deemed to have primary responsibility for the realization of such entitlements. Therefore, it becomes even harder to enforce such "obligations" upon other entities that may be deemed to have secondary or subsidiary responsibility, such as intergovernmental and nongovernmental organizations. In addition, it has even been argued that rights that are not justiciable cannot be regarded as having legal force. This

65 Gareth Evans, From Humanitarian Intervention to the Responsibility to Protect 24 WISCONSIN INTERNATIONAL LAW JOURNAL 703, 721 (2006).

66 Van Dyke \& Waldman, supra note 17, at 7.

67 Stephen P Marks, The Human Rights Framework for Development: Seven Approaches, in REFLECTIONS ON THE RIGHT TO DEVELOPMENT 29 (Arjun Sengupta, Archna Negi \& Moushumi Basu eds., 2005)

$68 \mathrm{Id}$.

$69 \mathrm{Id}$. at 31. 
is because some states refuse to consent to humanitarian assistance, or deny humanitarian agencies entry into disaster affected areas, or obstruct their activities, without suffering any sanctions.

Some lawyers, especially positivist ones, have argued that rights that "are not legally enforceable ... . cannot be regarded as human rights" and should, therefore, be viewed "as social aspirations or statements of objectives." ${ }^{70}$ Sengupta is opposed to such perceptions, and argues that such opinions result from reducing human rights to strict legal rights only. ${ }^{71} \mathrm{He}$ opines that "[h]uman rights precede law and are derived not from law but from the concept of human dignity. There is nothing in principle to prevent a right being an internationally [recognized] human right even if it is not individually justiciable." ${ }^{72}$ It is, therefore, correct to argue that rights are not always "legal instruments for individuals (though they can be, if governments codify them into law) but duties for governments, international agencies, and other actors to take concrete measures on behalf of individuals, or to restructure institutions so that the rights can be fulfilled more effectively."73

Besides the question of justiciability, some rights are complex since they involve a holistic set of requirements in order to be satisfied effectively. For instance, nutrition is certainly an aspect of the right to food. However, it is the link of such aspects as nutrition that make the right to food a complicated one. Jean Drèze notes that:

Ideally, the right to food should be seen as a right to 'nutrition' .... However, good nutrition itself depends in complex ways on a wide range of inputs: not just adequate food intake but also clean water, basic health care, good hygiene, and so on. Even if we confine our attention to food intake, the constituents of good nutrition are a matter of debate among nutritionists. ${ }^{74}$

In sum, the significance of the Sphere Project is that it links certain obligations arising from international human rights and humanitarian instruments with the role of civil society, and establishes, for the first time, globally applicable standards for the provision of humanitarian assistance

70 Arjun Sengupta, On the Theory and Practice of the Right to Development, in, REFLECTIONS ON THE RighT TO DEVELoPMENT 61, 76-77 (Arjun Sengupta, Archna Negi \& Moushumi Basu eds., 2005).

71 Id. at 77 .

72 Id.

73 Varun Gauri, Social Rights and Economics: Claims to Health Care and Education in Developing Countries in HUMAN Rights \& DEVELOPMENT: TOWARDS MUTUAL REINFORCEMENT 65, 72 (Philip Alston \& Mary Robinson eds.) ( 2005).

74 Drèze, supra note 58 at 1726 . 
by various agencies. ${ }^{75}$ In particular, it establishes minimum standards of conduct and accountability within humanitarian civil society organizations by linking them to existing and evolving obligations.

\section{PART II: EMERGING GLOBAL STANDARDS FOR HEALTH AND NUTRITION RELIEF}

Health and nutrition issues are inherently interrelated. Due to the fact that most humanitarian crises often lead to disturbances in food production and delivery, the issue of food aid is critical. ${ }^{76}$ Disasters affect the nutrition status of victims, which in turn will affect their health status. ${ }^{77}$ Nutrition problems arise from food production and distribution disruptions, which often occur during humanitarian crises leading to malnutrition. ${ }^{78}$ Questions of governance and regulation in the provision of health and nutrition aid are critical. This is due to the fact that relief assistance in humanitarian crises is often ineffective in reaching victims due to poor organization. ${ }^{79}$ That ineffectiveness in the provision of humanitarian aid compels institutions involved in relief aid to improve their accountability not only to their financiers but also to the beneficiaries. ${ }^{80}$ Improving accountability is one of the core concerns of the Sphere Project. ${ }^{81}$

In an attempt to drill down to specific operational benchmarks for health and nutrition recovery, the Sphere Humanitarian Charter comprehensively provides minimum standards, evaluation indicators, and guidance notes, on fundamental issues such as food security, nutrition assessment, micronutrient deficiencies and management of malnutrition. ${ }^{82}$ The Charter also includes important monitoring and evaluation tools such as checklists for food security and livelihoods assessment, seed security assessments, nutrition assessments, measurement of acute nutrition, measurement of the influence of micronutrient deficiencies on public health, and a nutrients requirement sample ${ }^{83}$ It also provides guidance on the management of health systems and effective provision of essential health services, which includes control of communicable and non-

75 Gostelow, supra note 9, at 317-18.

76 Kathy Mangones, Alternative Food Aid Strategies and Local Capacity Building in Haiti in, PATRONAGE OR PARTNERSHIP: LOCAL CAPACITY BUILDING IN HUMANITARIAN CRISES 51, 51 (Ian Smillie ed., 2001).

77 O'Donnell, supra note 4, at 230.

78 Id.

79 Id. at 231 .

$80 \mathrm{Id}$.

$81 \mathrm{Id}$.

82 THE SPHERE PROJECT, supra note 6.

83 THE SPHERE PROJECT, supra note 6. 
communicable diseases, reproductive health, management of injuries, children's healthcare and mental health. ${ }^{84}$ The Humanitarian Charter exhaustively provides minimum standards, appraisal indicators and guidance notes in critical areas of health relief. ${ }^{85}$ Important health assistance evaluation and quality analysis guidelines and instruments are also provided, such as a health assessment checklist, sample surveillance reporting forms on various medical conditions, mortality and morbidity, and formulas for calculating core health indicators. ${ }^{86}$

\section{Local Participation in Health and Nutrition Relief}

The importance of local community involvement in the design and implementation of relief efforts is now well understood. However, it is still often the case that challenges remain hampering effective engagement of local institutions such as religious bodies, professional groups, government agencies, community organizations and NGOs in relief efforts. ${ }^{87}$ From a historical perspective, relief efforts have been implemented from the top down, with activities focused on decisions and actions taken by external "experts." ${ }^{88}$ In addition, there has been a disproportionate reliance on foreign skills and resources, with external consultants, especially those from the donor's country, being granted privileged treatment. ${ }^{89}$ However, despite the occasional necessity of international skills and resources, excessive external reliance can stifle local capacity and hamper the local development of the healthcare sector. ${ }^{90}$ A large influx of international medical and paramedical staff often weakens local capacities, while parallel health projects and ad hoc recruitment of medical workers can cause the state health care system to decline. ${ }^{91}$ One of the suggested alternatives to ensure the strengthening of local capacities is to work with local health professionals (including the government staff), and pay their salaries directly by international aid agencies. ${ }^{92}$

84 Id.

$85 \mathrm{Id}$.

$86 I d$.

87 Ian Smillie, Capacity Building and the Humanitarian Enterprise in PATronaGe OR PARTNERSHIP: LOCAL CAPACITY BUILDING IN HUMANITARIAN CRISES 7, 7 (Ian Smillie ed., 2001)

88 Katrina M. Allen, Community-Based Disaster Preparedness and Climate Adaptation: Local Capacity Building in the Philippines 30 DISASTERS 81, 82-83 (2006).

89 Wolfgang Fengler \& Homi Kharas, Overview: Delivering Aid Differently in DeLIVERING AID DIFFERENTLY: LESSONS FROM THE FIELD (Wolfgang Fengler \& Homi Kharas eds. 2010) 1, 7.

90 Id.

91 A Paganini, National Health Workers in Crises: A Neglected Asset 18 HEALTH IN EMERGENCIES 1 (2003).

92 Paganini, supra at 1. 
There has been an emphasis on the need for "community-based approaches" that are more helpful in addressing the root causes of disaster vulnerability, rather than mere short-term responses. ${ }^{93}$ Local resources and skills need to be incorporated in humanitarian assistance projects in order to promote long-term solutions and improve efficacy. In most humanitarian crisis, initial and immediate response as well as long-term support comes from local entities and individuals, who provide critical assistance without outside support. ${ }^{94}$ If proper relationships and connections with external institutions did not exist prior to the humanitarian catastrophe, initiatives of external entities are often short lived or even frustrated. ${ }^{95}$

The Sphere Charter's standards and principles are based on a "people-centered" approach to humanitarian assistance. ${ }^{96}$ This implies the commitment by Sphere to develop a humanitarian assistance policy framework that considers local institutions as core participants in the provision of aid. The Sphere Humanitarian Charter is, therefore, a tool for promoting local participation in relief activities undertaken by external and international actors. The Humanitarian Charter states that its minimum standards are grounded in a "rights-based and people-centered approach to humanitarian response." 97 In particular, the Charter stresses that its principles and standards are premised on the necessity of incorporating local authorities and community members in decision-making processes. ${ }^{98}$ The Charter provides that:

Disaster preparedness requires that actors - governments, humanitarian agencies, local civil society organisations, communities and individuals - have the capacities, relationships and knowledge to prepare for and respond effectively to disaster or conflict. Before and during a response, they should start taking actions that will improve preparedness and reduce risk for the future. They should be prepared, at least, to meet the Sphere minimum standards during a future disaster. ${ }^{99}$

\footnotetext{
93 Allen, supra note 88, at 82-83.

94 LaRRY Minear, THE HumanitaRIan ENTERPRISE: Dilemmas AND DisCoveries 59 (2002); There is need to enhance the capacity of local institutions since most 'immediate search-and-rescue' activities are often undertaken by the local community as external assistance takes time before arrival. Rita Jalali, Civil Society and the State: Turkey after the Earthquake 26 DISASTERS 120, 122 (2002).

$95 \mathrm{Id}$.

96 THE SPHERE PROJECT, supra note 6.

$97 \mathrm{Id}$.

$98 \mathrm{Id}$.

99 THE SPHERE PROJECT, supra note 6.
} 
For purposes of promoting timely and decisive response to humanitarian crises, local capacities must be strengthened. ${ }^{100}$ While indigenous and local institutions are critical in initial responses to a humanitarian disaster, external aid at times is necessary especially in the case of a major calamity. ${ }^{101}$ However, response to a humanitarian crisis requires that local capacities be strengthened for long-term success. A humanitarian assistance project cannot be deemed to have succeeded where, despite a high survival rate, local medical staff and institutions are not equipped with independent capacity to respond to future calamities. ${ }^{102}$ However, despite evidence of the necessity of incorporating local resources and skills in relief efforts, there are often difficulties in effective integration of local participants in humanitarian activities of external agencies. ${ }^{103}$ Even where local participants are integrated into humanitarian projects, "the relationship is more often one of patronage than partnership. For a local organization, the task is more often about following the instructions of others than about meeting its own objectives."

Participation .... cannot be equated with empowerment - taking part in flawed systems merely perpetuates existing patterns of injustice. In order to advance the common good, individuals must possess both the capacity to assess the strengths and weaknesses of existing social structures and the freedom to choose between participating in those structures, working to reform them, or endeavoring to build new ones. ${ }^{105}$

Community-based approaches to the provision of relief provide an effective mechanism for the communication of needs and ideas in a "bottom up" framework. ${ }^{106}$ Such an approach has the advantage of strengthening the capacity of the locally affected population to cope and adapt to crises. It strengthens existing local knowledge, enhances local resources, and refines the adaptive capacities of the community. ${ }^{107}$ An example of a successful community based relief efforts was the housing reconstruction program in Aceh, Indonesia after the 2004 tsunami which

\footnotetext{
100 MINEAR, supra note 94 , at 65.

$101 \mathrm{Id}$. at 70 .

102 Id.

103 Smillie, supra note 87 , at 1.

104 Id.

105 Empowerment as a Mechanism for Social Transformation, UNITED NATIONS OFFICE (Nov. 15, 2012), http://www.bic.org/statements/empowerment-mechanism-social-transformation

106 Katrina M Allen, Community-Based Disaster Preparedness and Climate Adaptation: Local Capacity Building in the Philippines 30 DISASTERS 81,83 (2006). 
centered on applying local expertise and decision making to identifying resource priorities. ${ }^{108}$

Various strategies and methods have been postulated as a way of incorporating local participation in humanitarian activities, especially through community based forums. Such forums provide venues in which critical training and dissemination of technical knowledge on disaster prevention and management is provided. ${ }^{109}$ Forums can be organized to raise awareness of existing local hazards and risk factors. ${ }^{110}$ In addition, local skills and resources can be mobilized through community-based forums, and strategies can be devised for strengthening local adaptation capacities. ${ }^{111}$

Some suggestions have been put forward to strengthen local capacity in relief efforts. ${ }^{112}$ Scholars have proposed that the "bidding war" among foreign organizations that inflates local salaries and drains leadership from indigenous institutions, must end. ${ }^{113}$ It has been postulated that program strategy and coordination should include indigenous institutions as full partners. ${ }^{114}$ It has also been suggested that external actors should devise other informal ways to reach out to and incorporate local institutions and leaders. ${ }^{115}$

In addition, external agencies should identify local social networks and community groups and build into the "community-based and self-help initiatives" as a way of promoting local capacity. ${ }^{116}$ Relief agencies should create mechanisms under which the beneficiaries of relief can provide feedback and influence the conduct of humanitarian activities by the creation of systems that are efficient and transparent. ${ }^{117}$ Meetings and discussions with beneficiaries of relief require balanced representation. ${ }^{118}$ The beneficiaries of humanitarian assistance should be provided with adequate information in a language and format that they understand. ${ }^{119}$ The information should include the activities and projects of the

\footnotetext{
108 Fengler \& Kharas, supra note 108 , at 7.

109 Allen, supra at 86.

$110 \mathrm{Id}$.

111 Id. at 87.

112 MiNEAR, supra note 94, at 69.

$113 \mathrm{Id}$.

114 MINEAR, supra note 94, at 69.

$115 \mathrm{Id}$.

116 THE SPHERE PROJECT, supra note 4, at 55.

117 THE SPHERE PROJECT, supra note 4, at 55.

$118 \mathrm{Id}$.

$119 \mathrm{Id}$.
} 
humanitarian agency, and its obligations to the affected community. ${ }^{120}$ The humanitarian agency should facilitate community meetings and information sharing sessions by assisting them access to appropriate and safe venues. ${ }^{121}$ Agencies should create a complaints system that permits affected populations to lodge complaints in a safe and easy manner, and ensure that responses are provided and action taken in a timely and transparent way. ${ }^{122}$ As a way of promoting local economy and enhancing recovery by the community, efforts should be made to utilize, where possible, local labor and environmentally-sustainable materials. ${ }^{123}$ Progressive local cultural and religious practices should be taken into account and humanitarian agencies should design programs that accommodate and uphold them. ${ }^{24}$ As the humanitarian project progresses, there should be concerted efforts to increase the beneficiary community ownership of the various programs and their decision making power. ${ }^{125}$

Key indicators can be useful in evaluating whether local participation is present. ${ }^{126}$ Measures such as local capacity, feedback mechanisms, information sharing, accessible and safe spaces, right to complain, culturally appropriate practices and representative participation are among the indicators that can be tracked ${ }^{127}$ with the aim of institutionalizing a culture of partnership between external and local participants in humanitarian relief.

\section{PART III: COORDINATING INTERNATIONAL AND NATIONAL LEGAL FRAMEWORKS OF ACCOUNTABILITY}

There can be tensions between the objectives and activities of civil society organizations and those of the state government, leading to obstruction or suspicion of humanitarian activities. Minear cites the example of Mozambique where, in the mid 1990s there was evidence of donors, who, rather than promote a progressive and good relationship between the government agencies and civil society organizations, attempted to weaken the government. ${ }^{128}$ The domestic government can respond to such "unwanted" activities by resorting to measures intended to

120 Id.
121 Id.
122 Id.
123 Id.
124 Id.
125 Id.
126 Id.
127 Id.
128 MINEAR, supra note 94 , at 64. 
frustrate such agencies, and render the provision of humanitarian assistance virtually impossible. Some of the measures may include the adoption of legislation that restricts the activities of domestic and foreign civil society organizations, failure to guarantee the security of external humanitarian staff, visa and state entry restrictions, and excessive accountability and reporting requirements.

Partnership between states and civil society organizations is necessary for effective humanitarian assistance. As has been observed, state-civil society collaboration is essential, and the most effective relief efforts are characterized by strong governmental partnerships. ${ }^{129}$ Civil society organizations have, in reality, multiple roles in times of humanitarian crisis, including acting as an avenue through which the needs and concerns of affected populations can be publicized. They can also act as an intermediary between state agencies and victims of disaster. ${ }^{130}$ However, civil society organizations cannot perform the fundamental functions of the government; therefore they should respect the role of the state and operate in a manner that does not antagonize government agencies, or undermine progressive state policies.

The Sphere Humanitarian Charter has the objective of promoting a progressive collaboration between state and non-state humanitarian agencies, in order to establish the requisite synergy that can promote effective and quality humanitarian assistance. In particular, the Humanitarian Charter emphasizes the necessity of both "state and nonstate actors to respect the impartial, independent and non-partisan role of humanitarian agencies and to facilitate their work by removing unnecessary legal and practical barriers, providing for their safety and allowing timely and consistent access to affected populations.",131

In addition, the Humanitarian Charter makes some specific recommendations to state governments affected by humanitarian crisis. First, it calls upon states to respect the impartial and independent activities of non-state humanitarian agencies. ${ }^{132}$ Second, states are requested to facilitate timely humanitarian action by simplifying the procedures for issuance of entry, exit and transit visas. ${ }^{133}$ Third, governments are requested to ensure timely flow of relief materials and information,

129 Rita Jalali, Civil Society and the State: Turkey after the Earthquake 26 DISASTERS 120, 124 (2002).

$130 \mathrm{Id}$. at 123.

131 THE SPHERE PROJECT, supra note 4, at 21.

132 ld. at 373.

133 Id. 
without the application taxes, fees, licenses, etc. ${ }^{134}$ Fourth, the Humanitarian Charter acknowledges that, ultimately, the primary obligation to coordinate and plan relief efforts is the responsibility of the state, and therefore calls upon governments to provide planning services and coordinate disaster information effectively. ${ }^{135}$

As discussed, the Humanitarian Charter designates the primary role of co-ordination of humanitarian aid on the government, which forms the basis for sectorial and institutional collaboration. ${ }^{136}$ The Charter, however, recognizes that in circumstances where the state is the cause of the humanitarian crisis, or is unwilling or unable to provide coordination services, then alternative mechanisms are necessary. ${ }^{137}$ To fill that gap, the Charter proposes that humanitarian institutions can rely on the primary coordination services of a lead agency, in addition to seeking leadership from resourcefully endowed and acceptable intergovernmental organizations such as the United Nations. ${ }^{138}$

With regard to the necessity of civil society organizations acting in a non-political and unbiased manner, the Humanitarian Charter generally deems agencies operating within its minimum standards as also acting under the principle of impartiality. In particular, civil society organizations are obligated to act in accordance with the principle of impartiality, which the Charter defines as comprising the responsibility to provide assistance solely on the basis of the intensity of the need. ${ }^{139}$ In addition, the Charter links the principle of impartiality to that of non-discrimination, which requires that no victim of humanitarian disaster should be denied assistance on the basis of political views, social origin, nationality, race, gender etc. ${ }^{140}$ In sum, a civil society organization that pushes for certain political agendas, or provides assistance in a discriminatory manner, is acting in a manner inconsistent with the Sphere Humanitarian Charter.

There is a distinction between the principle of neutrality and that of impartiality. Neutrality requires that agencies providing humanitarian assistance not favor any section of the population, such as providing support to one of the parties in an armed conflict situation. ${ }^{141}$ In addition,

\footnotetext{
134 The SPHERE PROJECT, supra note 4, at 373-74.

$135 \mathrm{Id}$. at 373 .

$136 \mathrm{Id}$. at 60.

137 Id.

138 Id.

139 Id. at 22.

$140 \mathrm{Id}$.

141 Neil Greet, $A D F$ Experience on Humanitarian Operations: A New Idea? 4 SECURITY CHALLENGES 45, 46 (2008); OCHA on Message: Humanitarian Principles, OFFICE FOR THE COORDINATION OF
} 
the principle requires that humanitarian actors refrain from engaging in ideological, political, religious, or racial disputes within the states in which they provide assistance. ${ }^{142}$ On the other hand, the impartiality principle implies that there should be no distinction based on political views, nationality, race, class, religion, gender etc. in the provision of humanitarian assistance. ${ }^{143}$ Impartiality requires that humanitarian aid be provided solely on the basis of need, with the most serious cases being granted priority. ${ }^{144}$

A semblance of the form of impartiality that the Humanitarian Charter outlines may be the approach that the International Federation of the Red Cross and United Nations agencies adopts. For instance, Chandler observes as follows with regard to relief efforts during the Yugoslavia humanitarian crisis at the turn of the $21^{\text {st }}$ century:

In Serbia, European Union humanitarian aid programs operated on the highly selective basis of providing fuel and provisions to opposition-run municipalities while applying strict sanctions to the rest of the country. The UN Office for the Coordination of Humanitarian Affairs in Belgrade and the International Federation of the Red Cross challenged this approach by arguing that aid should be given on the basis of need and irrespective of political party affiliation. ${ }^{145}$

Throughout the Humanitarian Charter, despite silence on the principle of neutrality, the principle of impartiality and the various minimum standards limit the freedom of civil society organizations to make political choices. For instance, it limits the liberty of humanitarian agencies to do what has been referred to as making "judgments about what is right and just, about whose capacities are built, and which local groups are favored." ${ }^{\prime 46}$ Therefore, Charter replaces the idea of humanitarian assistance as "a lever for strategic aims drawn up and acted upon by external agencies" to that of "an expression of empathy with common humanity," without any form of discrimination. ${ }^{147}$

HUMANITARIAN AFFAIRS (OCHA) (2012),

https://ochanet.unocha.org/p/Documents/OOM-humanitarianprinciples_eng_June12.pdf.

142 Fiona Fox, New Humanitarianism: Does it Provide a Moral Banner for the 21st Century? 25

DISASTERS 275, 277 (2001); OCHA, supra.

143 OCHA, supra.

144 Id.

145 David Chandler, The Road to Military Humanitarianism: How the Human Rights NGOs Shaped a New Humanitarian Agenda 23 HUMAN RIGHTS QUARTERLY 678, 700 (2001).

146 Id.

$147 \mathrm{Id}$. 


\title{
CONCLUSION: COORDINATING HUMANITARIAN ASSISTANCE AND INSTITUTIONAL COLLABORATION
}

\begin{abstract}
Humanitarian assistance involves institutional and sectorial cooperation, and requires coordination between international and local participants. For instance, humanitarian assistance during the 1998 Bangladeshi flooding crisis involved approximately " 163 local, national and international NGOs who distributed relief items including food aid," and other forms of assistance such as medication to about 2.4 million victims. ${ }^{148}$ Due to the number of participants in the provision of humanitarian relief, including state and non-state actors, coordination of assistance activities was problematic. For instance, China, India, Turkey, South Korea, the Americas, Brazil, and Venezuela have all established large aid programs in recent years. ${ }^{149}$ They are essentially becoming part of "a landscape that has already expanded to include thousands of international NGOs and perhaps hundreds of thousands of communitybased and civil society organizations in developing countries themselves." 150 Fengler and Kharas, while highlighting the problem of coordination of developmental aid, observe:
\end{abstract}

[D]evelopmental aid, because it is fragmented into small projects, is uncoordinated and unreliable. These characteristics lead to waste and inefficiency. But problems of poverty remain deep rooted, and many individuals, countries, and agencies are eager and willing to contribute to the task of global development. Bringing these new players into the existing aid architecture is a critical new task. Efforts to expand the traditional model of centrally planned aid do not seem to be working, although some successes are evident. A new model is needed, with changes that are commensurate with the size of the problem. ${ }^{151}$

Despite the challenges of collaboration and coordination, it has been observed that the obligation to promote and realize human rights creates, in a sense, a duty for international co-operation. This is due to the fact that:

The international human rights normative framework has all along recognised the universality of the obligation to help

148 O'Donnell, supra note 4, at 230.

149 Fengler \& Kharas, stupra note 108 , at 6.

$150 \mathrm{Id}$.

$151 \mathrm{Id}$. at 39. 
realise human rights. Although the State has the primary obligation to take appropriate steps towards realising the human rights of all those living within its jurisdiction, outsiders have an obligation too because it is humanity as a whole that has conferred human rights on each other. ${ }^{152}$

In the preceding discussions, we have pointed out that the Sphere Charter requires the integration of local participants such as community groups in humanitarian assistance by external agencies. We have observed that the Sphere Charter provides a framework through which local participation may be transformed from patronage to partnership. In addition, we have discussed the Charter's focus on the host government as the bearer of the primary responsibility for ensuring coordination of humanitarian assistance. ${ }^{153}$ This implies that the host government bears the primary responsibility to create an effective framework for collaboration between various institutions and agencies involved in humanitarian aid. However, the Charter still recognizes that in some circumstances, such as in situations where the host government is the author of the crisis, is unable or unwilling to provide coordination services, humanitarian agencies require alternative coordination mechanisms. ${ }^{154}$ In such circumstances, the Charter implies that a lead agency can provide primary coordination services, while the United Nations, which has the benefit of resources and legitimacy, can also provide leadership. ${ }^{155}$

With regard to the primary role of the host government to provide coordination and planning services, an instructive illustration is the critical role that the Indonesian Government provided during the 2004 Indian Ocean tsunami. It has been observed that during and after the tsunami tragedy, donors from across the world provided billions of dollars to assist affected populations recover in locations such as the Province of Aceh. ${ }^{156}$ It has also been noted that the Indonesian Government effectively kept track of the various activities that were being undertaken by an approximately 500 agencies by establishing a novel coordinating institution. ${ }^{157}$ The Government's "coordination efforts helped identify gaps

\footnotetext{
152 Siddiqur Rahman Osmani, An Essay on the Human Rights Approach to Development, in REFLECTIONS ON THE Right to DeVElopment 1 10, 124 (Arjun Sengupta, Archna Negi \& Moushumi Basu eds.) (2005). 153 THE SPHERE PROJECT, supra note 4, at 60.

154 Id.

$155 \mathrm{ld}$.

156 Fengler \& Kharas, supra note 108 , at 2.

157 Id.
} 
in funding, and a multiyear trust fund improved predictability of aid flows reaching the people of Aceh." 158

The Sphere Charter provides a helpful model of self-regulation for guiding interagency collaboration and a widely recognized policy tool with regard to humanitarian guidelines and standards. ${ }^{159}$ Subsequent revisions and improvements of the Sphere Humanitarian Charter Handbook, since its first publication in 2000 , has been the result of broad consultation across various sectors, which have involved various civil society organizations, United Nations institutions, individuals, and other relevant agencies. ${ }^{160}$

There have been other mechanisms aimed at addressing the issue of coordination and collaboration in the provision of humanitarian relief, such as the 2005 Paris Declaration on Aid Effectiveness. ${ }^{161}$ The Paris Declaration affirms the need for humanitarian donors to align their objectives with the host state's objectives, and to utilize its systems in the delivery of aid. ${ }^{162}$ However, with regard to health and nutrition relief, it seems that the Sphere Humanitarian Charter provides the most comprehensive coordination mechanism that addresses the roles of both the host government and civil society organizations. This is due to the fact that it also includes, comprehensively, other relevant issues such as local participation and minimum standards in the provision of humanitarian assistance.

161 Fengler \& Kharas, supra note 108, at 20: see Paris Declaration on Aid Effectiveness (2005) and the Accra Agenda for Action (2008), http://www.oecd.org/dac/effectiveness/43911948.pdf

162 Id. at 20-21; see Paris Declaration on Aid Effectiveness (2005) and the Accra Agenda for Action (2008). 